\title{
LA PARTICIPACIÓN POLÍTICA COMO RESISTENCIA: EL CASO DE LA AGENCIA DE DERECHOS HUMANOS EN MONTES DE MARÍA, COLOMBIA
}

\section{POLITICAL PARTICIPATION AS RESISTANCE: THE CASE OF THE HUMAN RIGHTS AGENCY IN MONTES DE MARÍA, COLOMBIA}

\section{Rosaura Arrieta Flórez \\ Universidad de Cartagena, Cartagena de Indias, Colombia ipreg2@unicartagena.edu.co}

\section{Lina Luz Córdoba Girado}

Universidad de Cartagena, Cartagena de Indias, Colombia linacordoba7@gmail.com

\section{Katleen Marún Uparela}

Universidad Tecnológica de Bolívar, Cartagena de Indias, Colombia.

kmarun@utb.edu.co

\section{Rafaela Sayas Contreras}

Universidad de Cartagena, Cartagena de Indias, Colombia

rsayasc@unicartagena.edu.co

Palabras clave: Ciudadanía, Participación, Derechos humanos, Víctimas, Conflicto armado.

Keywords: Citizenship, Participation, Human rights, Victims, Armed conflict.

Resumen: La participación significa para las víctimas del conflicto armado en Colombia una apuesta por la agencia creativa para la reparación de los derechos vulnerados por el conflicto. Este trabajo presenta los resultados del acompañamiento a víctimas del conflicto en la construcción y seguimiento de los Planes Integrales de Reparación Colectiva. Se encontró que la participación en los espacios creados por el Estado viabiliza la incidencia de las víctimas en la planeación de las políticas públicas, pero, la desarticulación y el control fiscal institucional impiden el cumplimiento de los compromisos pactados, lo que se constituye para las víctimas en una coyuntura de lucha política y potenciamiento comunitario.

Abstract: Participation means for the victims of the armed conflict in Colombia a commitment to the creative agency for the reparation of the rights violated by the conflict. This paper presents the results of the accompaniment to victims of the conflict in the construction and follow-up of the Comprehensive Collective 
Reparation Plans. It was found that participation in the spaces created by the State makes it possible for victims to participate in the planning of public policies, however, the disarticulation and the institutional fiscal control prevent the fulfillment of the agreed commitments, which constitutes for the victims in a conjuncture of political struggle and community empowerment.

\section{l. Introducción}

El conflicto armado colombiano generó un fuerte impacto en todo el territorio nacional; sin embargo, hubo zonas que vivieron con mayor intensidad los estragos de la violencia. Una de esas zonas es la subregión de los Montes de María, ubicada en la región Caribe colombiana, conformada por 15 municipios de los departamentos de Bolívar y Sucre.

Montes de María se ha caracterizado por la presencia de movimientos campesinos desde la década de los sesenta, los cuales durante el periodo de violencia se vieron seriamente afectados en sus estructuras como la Asociación Nacional de Usuarios Campesinos (ANUC) y las Juntas de Acción Comunal de los territorios.

Precisamente unas veces al amparo de las instituciones y otras con sus propios recursos, las comunidades han gestado procesos de organización social, que transcienden la esfera de reclamación de derechos de personas victimizadas, para fortalecer capacidades en clave de ciudadanía.

Esta investigación busca poner en debate el derecho a la participación política de las víctimas, por ello la hipótesis central es que las voces silenciadas por la violencia han encontrado en los espacios institucionales de participación una práctica de resistencia; de tal forma que estas voces silenciadas utilizan estos espacios para exigir una reparación integral, transformadora de los daños causados, pero más allá de ello, para ser tenidos en cuenta en las decisiones que afectan el ejercicio de sus derechos y el destino de sus planes/ proyectos de vida.

Se utiliza la información compilada durante los años 2016 y 2017 con sujetos de reparación colectiva (SRC) de los Montes de María, en el marco del observatorio de reparaciones colectivas de la Universidad de Cartagena financiado por Codhes ${ }^{1}-U s a i d$.

Así las cosas, este trabajo da cuenta de comunidades que se han empoderado a través del ejercicio de la participación. La participación como derecho, conquistada en escenarios de violencia, constituye una práctica de resistencia, que fortalece capacidades en las personas y posibilita el ejercicio y la demanda de otros Derechos Humanos, entendiendo estos últimos como el resultado de la lucha social agenciada desde la participación política.

Para el desarrollo del texto se exponen en primer lugar unas consideraciones metodológicas, luego se presenta la evolución de los espacios normativos de participación para las víctimas, se plantean algunas consideraciones acerca de la participación concebida como derecho conquistado desde las luchas sociales desde la perspectiva planteada por Herrera Flores (2008) y el enfoque de capacidades de Sen (1999b) y Nussbaum (2001;2012); por último se exponen los resultados a partir del análisis de fuentes primarias y secundarias en torno a los es-

1. Consultoría para los derechos humanos y el desplazamiento. 
pacios y mecanismos de participación en la subregión de los Montes de María y la forma en la que se han configurado como forma de resistencia para las comunidades víctimas del conflicto.

\section{Consideraciones metodológicas}

Este trabajo parte de una Investigación Acción Participativa y Colaborativa-IAPC, con víctimas del conflicto Armado en Colombia, que bajo un enfoque cualitativo y de carácter descriptivo y analítico, pretendió reivindicar las voces de los sujetos participantes.

Los resultados se sustentan en el acompañamiento que durante dos años se hizo a procesos institucionales y comunitarios desarrollados en el marco de la formulación y seguimiento a los Planes de Reparación Colectiva -en adelante PIRC- de siete sujetos de reparación que hacen parte de la región de Montes de María en el caribe colombiano a saber: San José de Playón, El Salado, Berruguita y Alta Montaña, en el departamento de Bolívar; Flor del Monte, Chengue y Seis Veredas, en el departamento de Sucre.

Para el análisis del cumplimiento de los PIRC y de la incidencia de los sujetos de reparación en los espacios de participación que ofrece la ley se realizaron 14 grupos focales dinamizados con talleres participativos, dos por cada sujeto de reparación y 20 entrevistas semiestructuradas a líderes y lideresas de los Sujetos de Reparación y miembros de la comunidad.

Para evaluar la articulación interinstitucional y entre las víctimas e instituciones en el proceso de formulación, ejecución y seguimiento de los PIRC se construyeron mapas institucionales por sujeto de reparación; por último y con el fin de contrastar la visión de las victimas frente al proceso se realizaron 4 grupos focales con instituciones locales y departamentales que participan en los procesos de diagnóstico y ejecución de los planes de reparación.

\section{Referente contextual de la Guerra en Montes de María.}

El conflicto armado en Colombia presenta dinámicas y tendencias de violencia similares; es decir, presencia de guerrillas desde los años 70 - para el caso de la región de Montes de María del Ejército de Liberación Nacional- y a partir de la segunda mitad de la década de los ochenta se ubicaron en la zona las Fuerzas Armadas Revolucionarias de Colombia (FARC). Los años noventa consolidaron la presencia de las FARC, lo mismo que la irrupción de grupos paramilitares, lo que generó a finales de esta década fuertes enfrentamientos entre estos grupos que se disputaban el control territorial de la zona como refugio y corredor estratégico para el tráfico de armas y el narcotráfico (Victorino, 2011).

La disputa territorial dejó un elevado saldo de homicidios selectivos, masacres, amenazas, desaparecidos y en general violaciones sistemáticas de los derechos humanos en contra de la comunidad asentada en esta región y un consecuente desplazamiento forzado y abandono y despojo de sus tierras. La subregión de los Montes de María no fue ajena a esos fenómenos. Según Ojeda (2015) en toda la región de Montes de María entre los años 1996 y 2004 se registraron 56 masacres, más de 400 mil casos de desplazamiento y el despojo de más de 80.000 hectáreas de tierra. 


\section{Tabla I. Número de víctimas por hecho victimizante en Montes de María}

\begin{tabular}{|c|c|c|c|c|c|c|}
\hline \multicolumn{7}{|c|}{ Víctimas por hecho victimizante Montes de Maria, Bolívar 1985-2018 } \\
\hline & Homicidio selectivo & Desaparición Fozada & Masacres & Desplazamiento* & Secuestro & Violencia sexual \\
\hline \multicolumn{7}{|c|}{ Montes de Maria Bolívar } \\
\hline San Juan Nepomuceno & 236 & 92 & 41 & 30.247 & 67 & 30 \\
\hline Marialabaja & 172 & 69 & 29 & 34.438 & 77 & 83 \\
\hline El Guamo & 44 & 26 & 4 & 5.265 & 11 & 14 \\
\hline San Jacinto & 208 & 96 & 36 & 37.157 & 116 & 29 \\
\hline El Carme de Bolívar & 820 & 367 & 229 & 132.236 & 150 & 121 \\
\hline Zambrano & 105 & 142 & 25 & 20.136 & 14 & 171 \\
\hline Cordoba & 184 & 103 & 29 & 30.002 & 15 & 22 \\
\hline \multicolumn{7}{|c|}{ Montes de Maria Sucre } \\
\hline Ovejas & 194 & 92 & 10 & 48562 & 139 & 22 \\
\hline Los Palmitos & 92 & 17 & 3 & 12717 & 51 & 12 \\
\hline Morroa & 92 & 21 & 2 & 8768 & 12 & 3 \\
\hline Colosó & 196 & 45 & 6 & 25565 & 38 & 20 \\
\hline Chalan & 95 & 33 & 2 & 10058 & 21 & 8 \\
\hline Toluviejo & 261 & 70 & 7 & 18673 & 53 & 22 \\
\hline San Onofre & 289 & 223 & 7 & 52271 & 72 & 91 \\
\hline San Antonio de Palmito & 29 & 8 & 1 & 2632 & 8 & 14 \\
\hline Total MM & 3017 & 1404 & 431 & 468727 & 844 & 662 \\
\hline
\end{tabular}

Fuente: Los autores con base en Centro Nacional de Memoria Histórica.

* Personas expulsadas 1986-2018 (Corte Nov 1 de 2018)

Todos estos hechos violentos generaron profundos cambios en la propiedad y uso de la tierra que se reflejan en los altos índices de concentración de este recurso en los municipios de la región medidos por el coeficiente de Gini que según Daniels (2016) para el año 2015 se encontraban por encima del 0.7; en el aumento de las concesiones para la explotación de petróleo y gas (16 concesiones entregadas en 2016), y el aumento de la producción agrícola para uso industrial y exportador.

Adicionalmente, el rezago social y económico que existía aún antes del recrudecimiento de la violencia se profundizó con el conflicto de tal forma que para el año 2005, cinco de los siete municipios bolivarenses de la región tenían más del 70\% de su población pobre por necesidades básicas insatisfechas; y el 92\% de la población rural en la subregión tenía condiciones de pobreza medidas por el Índice de Pobreza Multidimensional.

Según Aguilera (2013) las mayores carencias se observan en el empleo formal, los logros educativos y el acceso a los servicios públicos domiciliarios. No obstante, lo más preocupante es el bajo nivel de escolaridad. Según el Censo de 2005, en la subregión es de 5,7 años de estudios aprobados para la población entre 15 y 64 años de edad, más bajo que los de Colombia $(8,2)$ y el de los departamentos de Bolívar $(7,9)$ y Sucre $(6,9)$.

En 2017 estos indicadores no han mejorado significativamente; las coberturas netas de educación en el nivel de media no superan en ningún municipio el $55 \%$ y se 
Tabla 2. Condiciones sociodemográficas Montes de María (2005 y 2017)

\begin{tabular}{|c|c|c|c|c|c|c|c|c|}
\hline \multicolumn{9}{|c|}{ Condiciones sociodemográficas Montes de María Bolívar } \\
\hline & \multirow[b]{2}{*}{ Area $(\mathrm{Km})$} & \multirow[b]{2}{*}{$\begin{array}{c}\text { Población } \\
\text { 2017* }\end{array}$} & \multirow[b]{2}{*}{$\begin{array}{l}\text { Densidad } \\
\text { poblacional }\end{array}$} & \multirow[b]{2}{*}{ NBI $2005^{* *}$} & \multicolumn{4}{|c|}{ Coberturas netas de educación (2017) } \\
\hline & & & & & Transcición & Primaria & Secundaria & Media \\
\hline San Juan Nepomuceno & 637 & 33753 & 53,0 & 61,7 & 63.2 & 94.7 & 82.5 & 52.5 \\
\hline Mariaabaja & 517 & 48787 & 94,4 & 70,4 & 47.4 & 82.8 & 69.9 & 40.8 \\
\hline El Guamo & 371 & 7771 & 20,9 & 74,2 & 37.4 & 86.9 & 72.8 & 44 \\
\hline San Jacinto & 434 & 21602 & 49,8 & 92,5 & 60.4 & 106.4 & 94.9 & 55 \\
\hline El Carmen de Bolívar & 900 & 76949 & 85,5 & 72,6 & 57.9 & 74.4 & 61.8 & 39.3 \\
\hline Zambrano & 287 & 11767 & 41,0 & 67,1 & 50.9 & 81.1 & 76.2 & 49.1 \\
\hline Cordoba & 573 & 12342 & 21,5 & 83,9 & 74.5 & 108.1 & 89.2 & 44.9 \\
\hline \multicolumn{9}{|l|}{ Montesde María Sucre } \\
\hline Ovejas & 447 & 21091 & 47,2 & 55,5 & 73.1 & 99.4 & 79.8 & 53.5 \\
\hline Los Palmitos & 125 & 19257 & 154,1 & 73,4 & 74.1 & 113.1 & 89.6 & 53 \\
\hline Morroa & 161 & 14429 & 89,6 & 61,5 & 50.9 & 75.3 & 55.8 & 28 \\
\hline Colosó & 141 & 5838 & 41,4 & 81,5 & 89.9 & 120.7 & 115.6 & 47.9 \\
\hline Chalan & 76 & 4354 & 57,3 & 71 & 35.1 & 76.2 & 72 & 51.7 \\
\hline Toluviejo & 276,5 & 18897 & 68,2 & 55,8 & 76.3 & 105.1 & 85 & 53.7 \\
\hline San Onofre & 1102 & 50214 & 47,8 & 65,1 & 70.9 & 90.7 & 65.3 & 33.3 \\
\hline San Antonio de Palmito & 176 & 13682 & 77,7 & 73,4 & 74 & 113 & 89.6 & 53 \\
\hline
\end{tabular}

Fuente: Los autores con base en Dane-Ministerio de Educación Nacional

Nota: *Proyecciones poblacionales Dane 2017. ** NBI Dane Censo.

registran coberturas por debajo del 30\% en municipios como Morroa, condenando a los jóvenes, en el mejor de los casos, a trabajos mal remunerados o como futuros reclutas de los grupos armados ilegales que aún quedan en la zona. (Ver tabla 2)

Transformar esta realidad es necesario para garantizar la consolidación de una paz estable y duradera y la reparación integral de las víctimas. En este sentido la ley 1448 , ley de víctimas y restitución de tierras define a la participación como un eje transversal de los procesos de reparación integral; por tanto, todas las entidades del Sistema Nacional de Atención y Reparación Integral a la Victimas (SNARIV) tienen el deber de garantizar el derecho de las víctimas a informarse, intervenir, presentar observaciones, re- cibir retroalimentación y coadyuvar -de manera voluntaria- en el diseño de los instrumentos de implementación, seguimiento y evaluación de las disposiciones previstas en la ley y los planes, programas y proyectos implementados por las autoridades para fines de concretarse su cumplimiento.

Es decir, esta normativa sienta las bases para que las víctimas tengan incidencia real en las decisiones y acciones gubernamentales que puedan afectar su presente y futuro, mediante contribuciones individuales y colectivas formuladas de acuerdo a sus necesidades. 


\section{Víctimas y participación: evolución de los espacios normativos}

El conflicto armado colombiano constriñó seriamente el derecho a la participación, a la libre expresión y al libre pensamiento de muchas poblaciones, coartando a partir de amenazas y terror, los espacios de participación comunitaria y silenciando voces que luchaban por derechos históricamente vulnerados.

Sin embargo, ello no ha sido una constante absoluta durante este periodo, a la par del terror y las amenazas se gestaban movimientos, formas asociativas de víctimas que propendían por la garantía de derechos incipientemente reconocidos. Ello dio lugar a que ciertas luchas desde lo popular abrieran los espacios institucionales para una participación, al menos en términos formales. (Nieto, 2014).

Producto de ello en 1997 fue promulgada la Ley 387, a través de la cual fueron adoptadas por primera vez en el estado colombiano medidas orientadas a prevenir el desplazamiento forzado y a consolidar una estrategia de atención, protección y estabilización social y económica de esta población, que había sido omitida de la agenda pública.

El carácter fundacional de esta norma para los derechos de las víctimas es innegable, ya que constituyó el primer antecedente normativo que evidenció la crisis que el país experimentaba en relación con los derechos de la población desplazada por el conflicto armado y la violencia.

En el debate de la participación de las víctimas no puede obviarse la mención de una de sus más grandes conquistas: la declaratoria de un estado de cosas inconstitucional $(\mathrm{ECl})$ por parte de la Corte Constitucional colombiana. Esta se dio a través de la Sentencia T-025 de 2004 que decidía sobre un conjunto de 108 expedientes de acciones de tutela interpuestas por 1.150 familias víctimas en contra de entidades del Estado encargadas de su atención como la Red de Solidaridad Social, el Departamento Administrativo de la Presidencia de la República, el Ministerio de Hacienda y Crédito Público, el Ministerio de Protección Social, el Ministerio de Agricultura, el Ministerio de Educación, entre otros, por el incumplimiento reiterado y la negligencia en la garantía de los derechos de esta población.

Esta declaratoria no fue más que el reconocimiento de la incapacidad del Estado colombiano de hacer frente a la crisis generada por el incumplimiento de su obligación de garantizar los derechos de las víctimas del conflicto, afectadas por la vulneración sistemática y masiva de sus derechos.

De allí se derivaron una serie de autos de seguimiento ordenados por la Sentencia para la evaluación previa al levantamiento del ECI, que constituyeron un antecedente importante en materia de espacios de participación y seguimiento a políticas públicas, ya que fue conformada inicialmente la Comisión de Seguimiento a la Política Pública sobre Desplazamiento Forzado (CSPPDF) y se determinan a lo largo de este periodo de seguimiento un conjunto de Indicadores de Goce Efectivo de Derechos (IGED), para evaluar el estado de los derechos vulnerados.

Esto permitió entonces que no solo la CSPPDF tomara el protagonismo del seguimiento, sino que además colectivos de víctimas, organizaciones no gubernamen- 
tales y movimientos hicieran parte de los procesos de documentación y evaluación sobre el estado de los derechos en cuestión, como un insumo clave para impedir que el ECI fuese levantado a pesar de la persistencia de los factores que dieron origen a esta declaratoria.

Lo anterior generó efectos indirectos o simbólicos sobre la participación y el lugar de las víctimas, asociaciones, organizaciones y defensores de sus derechos en las decisiones. Rodríguez, C y Rodríguez, D, coinciden en que este proceso pudo haber contribuido a "cambiar la percepción pública sobre la urgencia y gravedad del desplazamiento en Colombia, o haber legitimado las denuncias y reforzado el poder de negociación de las ONG de derechos humanos y las entidades internacionales que venían presionado al gobierno" (2010: 23).

Luego de esta norma, entró a regir en Colombia la Ley 975 de 2005, producto del acuerdo celebrado con las Autodefensas Unidas de Colombia. La llamada Ley de Justicia y Paz ofrecía a los miembros de estos grupos una pena alternativa de ocho años de cárcel por los delitos cometidos a cambio de garantizar los derechos de las víctimas a la verdad, justicia y reparación integral. Sin embargo la norma no tuvo los efectos esperados; de acuerdo a lo señalado por la Contraloría General de la Nación, (2017) en diez años de vigencia de la norma solo fueron proferidas 47 sentencias, condenando a 195 postulados, un equivalente al $8.2 \%$ (2.378) de la población que la norma debía impactar. Al igual que las indemnizaciones ordenadas en favor de las víctimas fueron cubiertas con presupuesto del Estado, ya que los bienes usurpados no fueron devueltos en su mayoría.
En este contexto allanado por el ECl, y agudizado por las barreras que enfrentaba la Ley 975 de 2005, entra en vigencia la Ley 1448 de 2011, conocida como Ley de víctimas y restitución de tierras. Producto justamente de los procesos de visibilización, exigencia de derechos y demandas insatisfechas que desde la década anterior venían jalonando movimientos y colectivos de víctimas. Así las cosas, con esta Ley se abre paso a un periodo de nuevas posibilidades y mecanismos jurídicos en cabeza de las víctimas para la exigencia de sus derechos.

Esta norma entre otros aspectos, toma la participación de las víctimas como principio importante orientador de los procesos de reparación, y en ese sentido configura algunos espacios de interlocución y participación política para las víctimas desde distintos escenarios a nivel local, regional y nacional como forma de garantizar su participación efectiva y la incidencia en las decisiones que afectan la materialización de sus derechos.

Algunos de los espacios de participación propuestos por la ley son: i) las mesas de participación de víctimas a nivel municipal, distrital, departamental y nacional ii) el Consejo Directivo de la Unidad Administrativa Especial de Gestión de Restitución de Tierras Despojadas iii) los Comités Territoriales de Justicia Transicional iv) la Comisión de Seguimiento y Monitoreo v) el Comité Ejecutivo para la Atención y Reparación a las Víctimas.

Según la guía práctica sobre el Protocolo de Participación UARIV (2013), estos espacios de trabajo temático y de participación efectiva; elegidos y designados por las mismas víctimas y sus organizaciones tienen como objetivo garantizar su incidencia y representación en los procesos 


\section{Tabla 3. Consejos Comunitarios Montes de María, Bolívar 2018}

\begin{tabular}{|lll|}
\hline No. & Nombre & Zona Rural /Urbana \\
\hline 1 & Consejo Comunitario Marialabaja & Urbana \\
\hline 2 & Consejo Comunitario El Níspero & Rural/ Corregimiento \\
\hline 3 & Consejo Comunitario Flamenco & Rural/ Corregimiento \\
\hline 4 & Consejo Comunitario Los Bellos & Rural / Vereda Retiro Nuevo \\
\hline 5 & Consejo Comunitario Guarismo & Rural/ Vereda de Nueva Florida \\
\hline 6 & Consejo Comunitario Arroyo Grande & Rural/ Corregimiento \\
\hline 7 & Consejo Comunitario Correa & Rural/Corregimiento Correa \\
\hline 8 & Consejo Comunitario Matuya & Rural/Corregimiento Matuya \\
\hline 9 & Consejo Comunitario Rosas de Mampuján & Urbana/ Cabecera de Maríalabaja \\
\hline 10 & Consejo Comunitario El Sena / Paso el Tiempo & Rural/Caserío de San Pablo \\
\hline 11 & Consejo Comunitario San Pablo & Rural/ Corregimiento \\
\hline 12 & Consejo Comunitario Nuevo Maja & Rural/Agrupa a los caseríos Nuevo Retén y Majagua \\
\hline 13 & Consejo Comunitario de Colú & Rural/Nereda de Playón \\
\hline 14 & Consejo Comunitario de Ñanguma & Rural/Corregimiento \\
\hline 15 & Consejo comunitario Almirante Padilla & Los Robles, el Guamo. \\
\hline 16 & Consejo comunitario, María Majarí & El Níspero \\
\hline & &
\end{tabular}

Fuente: Defensoría del Pueblo, 2018.

de reparación integral, constituyéndose en la oportunidad para la discusión, interlocución, retroalimentación, diseño, ejecución, capacitación y seguimiento de las disposiciones contempladas en la Ley 1448, así como también de las políticas públicas, programas o planes diseñados bajo el marco de dicha ley.

En este mismo sentido, en el Acuerdo Final para la terminación del conflicto con las FARC se planteó que:

La participación ciudadana es el fundamento de todos los acuerdos que constituyen el acuerdo final. Participación en general de la sociedad en la construcción de paz y participación en particular en la planeación, la ejecución y el seguimiento a los planes y programas en los territorios, que es además una garantía de la transparencia. (Acuerdo final: 4).

Para tal efecto se crearon instrumentos como: Ios Planes Desarrollo con Enfoque Territorial (PDET), los Planes de Acción para la Transformación Territorial (PATR) y las Circunscripciones Especiales de Paz.
Los PDET son un instrumento de planificación y gestión para implementar reformas con un horizonte temporal de 10 años en los territorios rurales más afectados por el conflicto armado, la pobreza, las economías ilícitas y la debilidad institucional (ART, 2017).

Por su parte, Ios PATR son mecanismos a través de los cuales se instrumentalizan Ios PDET, tienen una característica muy importante ya que son construidos de manera participativa, amplia y pluralista en las zonas priorizadas, y se revisarán y actualizarán en el territorio cada 5 años de forma participativa.

Con el objetivo de garantizar el pluralismo, facilitar la constitución de nuevos partidos y movimientos políticos que contribuyan al debate democrático con garantías para el ejercicio, el Acuerdo final creó 16 zonas transitorias especiales de paz, las cuales tendrán representantes a la cámara por dos periodos, estas curules son reservadas para movimientos y organizaciones de los territorios 
que no han tenido representación en el Congreso.

Paralelamente, otros procesos organizativos se han fortalecido en el posconflicto, es el caso de comunidades étnicas afrodescendientes a través de la conformación de Consejos Comunitarios de Comunidades Negras y Afrocolombianas, reconocidos en la Ley 70 de 1993. Un Consejo Comunitario es una unidad administrativa que vela por la conservación y protección de los derechos de la propiedad colectiva, la identidad cultural y los recursos naturales, entre otras funciones.

Según la Defensoría del Pueblo en 2018 en el departamento de Bolívar existían 54 Consejos comunitarios, de los cuales 16 son de comunidades de los Montes de María. La disminución de la intensidad del conflicto en 2005 favoreció el despertar de grupos que se animaron a participar más activamente y a exigir sus derechos, la mayoría como víctimas, para luego hacer un tránsito más lento a los temas de pertenencia étnica y en consecuencia la defensa de las consultas previas y las posibilidades de proteger su territorio por la vía de la titulación colectiva de la tierra.

\section{Participación política de las víctimas, capacidades y prácticas de resistencia}

La experiencia colombiana de transición y posconflicto ha puesto en evidencia que el camino hacia la participación real y efectiva de las víctimas en los procesos que les conciernen se ha constituido como una práctica de resistencia y re-existencia, ya que como será analizado más adelante, a pesar de las constantes barreras y desafíos a la participación, los colectivos, asociaciones, sujetos de reparación colectiva y organizaciones siguen redefiniéndose a partir de las conquistas y agendas pendientes; y en este proceso generan una serie de capacidades y agencia de otros derechos.

Esto pone en evidencia los planteamientos de Herrera (2008) desde la teoría crítica de los Derechos Humanos y su entendimiento de estos como el resultado de procesos sociales y no como meros reconocimientos jurídicos que han surgido en un momento específico, sin comprender que obedecen a una construcción histórica, cultural y políticamente situada.

Lo anterior ubica las discusiones en el plano del Desarrollo Humano y la democracia deliberativa. Dentro de lo cual cabe resaltar que en los aportes de Sen (1999a) a la teoría del Desarrollo Humano al debate público y a la deliberación les es asignada una posición central; así, asumiendo inicialmente la libertad como ejercicio de poder (Muñoz, 2014), se defienden la libertad política y la democracia como claves para el desarrollo desde tres argumentos centrales.

El primero es la importancia en esencia de la libertad política, comprendida como capacidad humana básica y como la capacidad de participar de la política y de la vida social. El segundo lo constituye el valor instrumental de la libertad política, pues su fin es justamente someter a debate, poner en discusión y expresar de forma pública cualquier aspecto valorado por la persona en el contexto político. Y el tercero, el valor constructivo de la libertad política, pues los derechos cuya materialización hace posible el debate y la discusión son vitales para la construcción de valores para el desarrollo. (Sen, 
1999b) (Hueso, Boni and Belda-Miquel, 2015).

Es de este modo como la participación es puesta en valor de modo preponderante por su valor intrínseco (como parte del bienestar humano), su valor instrumental (como medio para la defensa de los propios intereses) y su valor constructivo (clave en la formación de creencias, valores y deseos) desde el Desarrollo Humano y el enfoque de capacidades (Hueso, Boni and Belda-Miquel, 2015).

Así las cosas es posible anclar la noción de participación desde su valor instrumental a la "participación ciudadana" que incluye diversas formas de acción colectiva, exigencia de derechos, de reivindicación o incluso de respuesta a convocatorias originadas desde el gobierno para la incidencia en las decisiones sobre las políticas públicas. Es decir, es una participación que desde lo ciudadano atiende a una voluntad de incidencia.(Parés, 2009).

En ese sentido la participación puede verse de acuerdo con Aldret (2017) como un elemento disruptivo, desde un rol de protección del ciudadano frente al gobierno o incluso adquirir una función primordial en la deliberación y toma de decisiones políticas. Esta última noción y la voluntad de incidencia (Parés, 2009), están ligadas a su vez a los planteamientos de Nussbaum en relación con la capacidad central de control político sobre el propio entorno, ya que la identifica como aquella que nos permite "participar de forma efectiva en las decisiones políticas que gobiernan nuestra vida; tener derecho a la participación política y a la protección de la libertad de expresión y de asociación”. (Nussbaum, 2012:54).

Sin embargo, en un contexto en el que se pretende evaluar el nivel de incidencia y participación real y efectiva de las víctimas resulta importante comprender la participación política no solo desde la dimensión de las capacidades, sino además desde los funcionamientos, ya que justamente estos evidencian los logros que los sujetos están en condición de alcanzar a partir de las capacidades que desarrollan.

Es de esta manera como resulta mucho más útil la perspectiva de los funcionamientos en el caso planteado, puesto que "expresan el uso efectivo de la libertad (capacidad), donde puede observarse empíricamente qué hace la ciudadanía con los recursos de participación política, considerando las circunstancias personales y sociales de una ciudadanía siempre heterogénea"(Muñoz, 2014:89).

Por su parte, Nieto (2014) plantea el tema de la participación política como una práctica de resistencia en el marco del conflicto armado y de las víctimas, mencionando que este periodo de violencia no debe ser entendido únicamente desde una perspectiva esencialmente negativa y con consecuencias dañinas, sino como un fenómeno que al mismo tiempo que ha dejado un saldo importante de víctimas, ha desencadenado procesos de resistencia social en diversos sectores de la ciudadanía que bajo el estatuto de "víctimas" han emprendido luchas por la reclamación de sus derechos, no solo en tanto víctimas, sino también como ciudadanos.

Lo anterior ha permitido a su vez la generación de toda una estructura social de fortalecimiento de capacidades asociadas a estas reclamaciones, a la agencia de sus derechos, y al empoderamiento "como sujetos de derecho y como actores sociales protagonistas de su propio desarrollo" (Villa and Insuasty, 2016:454) (Nieto, 2014). 
De otra parte, cobra importancia el abordaje crítico de los espacios creados desde lo institucional para la interlocución con las víctimas, ya que a pesar de originarse en respuesta a reclamos de éstas y como una forma "efectiva" de participación, no han tenido en conjunto la incidencia política esperada, como se verá más adelante.

Vargas (2014) expone algunos de los principales desafíos que la política de atención y reparación integral a víctimas ha tenido que enfrentar y que han incidido de manera importante en aspectos como la participación real y efectiva de las víctimas y la materialización de sus derechos, señalando que esta política ha sido:

Una política pública marcada por la dispersión institucional y normativa, en un gobierno multinivel (local, departamental y nacional) desarticulado. El gobierno propendió por la creación de un sistema de implementación de la política de atención y reparación a víctimas altamente descentralizado, pero no estableció un sistema claro de corresponsabilidad entre la nación y los entes territoriales que permitiera la transferencia de los recursos y las capacidades técnicas a los entes territoriales que en lo local no cuentan con la capacidad económica, técnica y fiscal para responder a las demandas de las víctimas y garantizar sus derechos. (Vargas, 2014: 202)

En ese plano de desarticulación institucional y normativa para Subirats (2005) es importante comprender que la política no se agota en las instituciones, ni el escenario participativo puramente institucional, para anotar seguidamente que:

...política quiere decir capacidad de dar respuesta a problemas colectivos. Por tanto, parece importante avanzar en nuevas formas de participación colectiva y de innovación democrática que no se desvinculen del cam- bio concreto de las condiciones de vida de la gente. No tiene demasiado sentido seguir hablando de democracia participativa, de nuevas formas de participación política, si nos limitamos a trabajar en el estrecho campo institucional. (2005: 6).

Esto para traer nuevamente a colación el valor intrínseco e instrumental de la participación, comprendida desde su funcionamiento como capacidad de control político sobre el propio entorno. Así el funcionamiento de esta capacidad estará dado por la verdadera incidencia política de las víctimas en las decisiones que les ocupan.

Al respecto de esto señala Vargas (2014) que esta incidencia se enfrenta a una serie de "problemas estructurales" entre los cuales señala la atomización de las organizaciones debido a la competencia interna generada por el acceso a los pocos cupos de participación existentes, dado que estos son establecidos sin responder a dinámicas organizativas de las víctimas en lo local, provocando problemas en la acción colectiva, competencia entre los mismos colectivos de víctimas y al interior de las comunidades, justamente por la falta de diálogo entre las instituciones y éstas.

Esto desvía la atención más hacia la captación de recursos y a la competencia individual entre organizaciones, colectivos y movimientos, que hacia "la puesta en marcha de repertorios de movilización disruptivos que les permitan convertirse en una amenaza para el Estado, o en un movimiento capaz de generar presión para alcanzar sus reclamos"(Vargas, 2014: 203), como se expondrá seguidamente en la sección de resultados y discusión.

Finalmente, resulta importante señalar que la participación política real y efectiva de las víctimas implica retos de carácter técnico que "no se cubren con la simple 
declaración de voluntad y tampoco con la sola existencia de una normatividad que obligue a las autoridades a consultar a la ciudadanía para la elaboración de planes y programas de gobierno"(Aldret, 2017:352), ya que como afirma Herrera (2008) el ejercicio efectivo de los derechos humanos depende necesariamente de la existencia de una serie de condiciones materiales, políticas, económicas y culturales.

De este modo, se evita caer en el "error" de confundir la dimensión "empírica" del derecho a la participación política de las víctimas con su dimensión "normativa". Esto precisamente porque cuando el debate se da en un lenguaje de derechos no se parte "de lo que tenemos, sino de lo que debemos tener", (Herrera, 2008:33), así mientras que el derecho obedece a niveles de abstracción jurídica planteadas desde lo deontológico, su ejercicio depende las condiciones materiales de existencia, con independencia de lo establecido normativamente.

\section{Resultados y discusión}

En la construcción conjunta de alternativas para la reparación las víctimas han trasformado la participación en el mecanismo para la exigibilidad de los derechos que fueron vulnerados en el marco del conflicto armado; ahora los derechos sociales, económicos políticos y culturales que fueron transgredidos por el Estado y los actores armados, pueden ser reclamados mediante la participación en las instancias de deliberación propuestas por la Ley 1448 y el Acuerdo Final de paz.

En el trabajo cooperativo con los Sujetos de Reparación Colectiva de Montes de María se señaló que participar en los espacios de interlocución promulgados por la Ley 1448 de 2011 y el Acuerdo de Paz, constituye un espacio de resistencia frente al debilitamiento institucional en la medida que hace posible i) la incidencia en la planeación y las políticas públicas y ii) el fortalecimiento del tejido social y la generación de capacidades.

\section{I. Incidencia en la planeación y las políticas públicas}

\section{1.l. Planes Integrales de Reparación Colectiva}

Los Planes Integrales de Reparación Colectiva (PIRC) se enmarcan como resultado de la implementación de la Ruta de Reparación Colectiva (RRC); y están constituidos por un conjunto de acciones integrales ligadas a las medidas de restitución, rehabilitación, satisfacción, garantías de no repetición e indemnización en los componentes social, político y económico, fines de la Ley de Victimas y restitución de Tierras.

La participación de las victimas transversaliza el proceso de la reparación colectiva, en cada una de las fases de la RRC es indispensable el reconocimiento de las víctimas como sujetos sentipensantes, desde cuyos conocimientos deben construirse las alternativas para la creación del mundo que imaginan; es decir, el diseño de los PIRC abre la oportunidad para que las víctimas sean autoras de las políticas que el Estado deberá ejecutar para el acceso a los bienes materiales e inmateriales posibilitadores de una vida digna y transformadora.

En consonancia, un elemento significativo de la RRC es la coyuntura que 
representa para la reivindicación de la memoria de las voces silenciadas por la violencia y visibilizar los hechos victimizantes a través de las narrativas auténticas de las víctimas. Un primer espacio, lo posibilita la fase de diagnóstico del daño; en la que se pretende escuchar de primera mano las voces de los sujetos en el relato de los sucesos ocurridos a raíz del conflicto; en este escenario confluyen personas atravesadas por sus realidades y hechos de victimización que, movidas por la necesidad de reparación se abren a la comunidad y al Estado para trenzar la narrativa colectiva de los hechos.

La participación en este espacio no solo permite que se piense la reparación desde los sujetos que sienten los efectos de un pasado violento, sino que viabiliza ejercer control y seguimiento al cumplimiento de los compromisos pactados. De igual modo, permite un diálogo político entre la institucionalidad y los sujetos de reparación que coadyuva al desarrollo de capacidades políticas, ciudadanas y de autogestión comunitaria.

En los encuentros con los SRC se señaló que a nivel político lograron influir en el cumplimiento de varias medidas de reparación por parte del Estado Colombiano, tal es el caso del SRC de El Salado; quien en su Plan de Reparación Colectiva demandó la terminación y mejoramiento de la carretera El Carmen- El Salado; la reparación y ampliación de la calidad del alcantarillado comunitario, la ampliación del Acueducto del Salado; la transformación del monumento de las víctimas en una casa de memoria; y la instalación de un puesto de policía en el corregimiento; las cuales fueron ejecutadas por la Gobernación de Bolívar, la Fundación Semana, la Alcaldía Municipal y el Centro de Memoria respectivamente. (Grupo focal El Salado, 2017)

No obstante, Ios SRC coincidieron en subrayar que pese a la incidencia política que facilitó el ejercicio de la participación en el diseño de los Planes de Reparación Colectiva y el cumplimiento de algunas medidas en el territorio; la Unidad de Atención y Reparación Integral a Victimas (UARIV) (institución creada por el Estado Colombiano para dinamizar los procesos de reparación) no ha gestado las articulaciones interinstitucionales correspondientes para el cumplimiento de todas las acciones propuestas en ellos.

"Siempre nos quedamos en las mismas porque nos reunimos solo con la Unidad y no con los responsables de las medidas, cuando la medida le toca a la Alcaldía, no está ningún funcionario de la Alcaldía y así, pareciera que fuera una cosa planeada, para que uno se aburra" (Entrevista, SRC Alta Montaña, 2017).

"La Alcaldía nos ha apoyado un poquito en el transporte y mejoro un poquito la vía. En reparación lo que pasa es que lo trabaja la Unidad y en ese sentido ellos se desentienden entonces lo que deben es articularse. Así mismo esta lo del equipo de trabajo, el alcalde da responsabilidades pero solo trabajan cuando él está allí, cuando él se va siguen como si nada". (Entrevista, SRC Chengue, 2017).

En este contexto, se esperaría que los órganos de control creados con el objetivo de defender, proteger y prevenir cualquier abuso a los derechos humanos de la ciudadanía; interviniera en el acompañamiento a los SRC para cumplir su objeto misional, pero, advirtieron las victimas sobre la falta de voluntad política de los mismos en la unión de esfuerzos 
para garantizar el cumplimiento de las medidas de reparación.

"La Contraloría, Procuraduría, Defensoría, que son los entes que hacen que las cosas se den, no funcionan aquí en el Salado. En este país la ley para las víctimas no existen, están bonitas en el papel" (Participante grupo focal Grupo, SRC El Salado, 2017).

"Creíamos que la Defensoría iba a estar defendiéndonos, pero nosotros tenemos que estar detrás de la defensoría y es poco lo que ha hecho. Nosotros siempre que nos reunimos los convocamos y vienen, nos ayudan, pero no han avanzado" (Participante grupo focal SRC Alta Montaña, 2017).

La Ley 1448 de 2011 en su artículo 174, ordena a las Alcaldías Municipales y Gobernaciones Departamentales "diseñar e implementar, a través de los procedimientos correspondientes programas de prevención, asistencia, atención, protección y reparación integral a las víctimas, los cuales deberán contar con las asignaciones presupuestales dentro los respectivos planes de desarrollo y deberán ceñirse a los lineamientos establecidos en el Plan Nacional para la Atención y Reparación Integral a las Víctimas"2

Los SRC manifiestan que los entes territoriales no solo desatienden este compromiso descuidando el acompañamiento institucional en la reparación, sino que también incumplen la asignación y ejecución presupuestal obligada por la Ley.

"La Alcaldía aunque tiene presencia en el territorio está distante de los gestiones que se desarrollan en el Salado. Tiene la responsabilidad de legalizar los predios donde funciona el cementerio, la iglesia y el colegio, pero aún no ha desarrollado acciones para su cumplimiento. Con la gobernación de

2. Ley de víctimas y restitución de tierras, 1448 de 2011.
Bolivar, sucede algo parecido, ésta en el Salado ha construido varias infraestructuras, como la cancha de futbol, la casa deportiva, pero, tiene compromisos pendientes con el corregimiento" (Entrevista, SRC El Salado, 2017)

“Ninguna institución está presente de manera permanente en el territorio porque siempre dicen que no tienen presupuesto y no se puede trabajar". (Participante Grupo focal, SRC Playón, 2017).

En contraposición a las debilidades señaladas los SRC alegaron que se han armado con los mecanismos de participación ciudadana para ejercer presión a la actuación de la UARIV, Órganos de Control, Entes Territoriales y entidades competentes de la atención y reparación a las víctimas, de tal forma que la veeduría ciudadana y el control social a la gestión de estas instituciones sean las estrategias para impulsar la intervención efectiva en los territorios:

"Hemos hecho derechos de petición a la Unidad de Víctimas y la Defensoría del Pueblo para que entreguen informes pero siguen sin responder por eso se procedió a realizar tutelas". (Entrevista, SRC Berruguita, 2017).

Es tal el poder descubierto en la participación por las víctimas, que la transformaron en dispositivo de resistencia, presión, reclamación y control de la actuación Estatal, debido a las inoperancias, ineficiencias, desarticulaciones institucionales, incumplimiento de compromisos, entre otros; disposiciones antagónicas bajo la capacidad de auto-gestión de los proyectos de vida colectivos, creativamente pensados desde las bases comunitarias. 


\section{6.l.2. Planes Desarrollo con Enfoque Territorial (PDET)}

Los Planes Desarrollo con Enfoque Territorial son otro espacio de participación e incidencia ciudadana diseñados en el marco de la implementación de los Acuerdos de paz. Según el Decreto 893 del 24 de mayo del 2017 tienen como principal objetivo "sentar las bases para la transformación estructural del campo, crear condiciones de bienestar para la población rural y de esa manera, contribuir a la construcción de una paz estable y duradera."

En la subregión de Montes de María se desarrollaron en la etapa de alistamiento 70 simulacros de asambleas con una participación de 2.700 personas. Posteriormente se realizaron 78 pre-asambleas. La fase municipal dejó como resultado dieciséis (16) pactos comunitarios (nivel veredal) y 15 Pactos para la Transformación Regional (PCTR), los cuales tienen una cobertura regional. En la construcción de estos acuerdos participaron más de once mil actores del territorio y 15 administraciones municipales. (Agencia de renovación del territorio, ART, 2017)

Vale la pena destacar la importancia de este proceso participativo para la región y sus habitantes, no solo por su potencial transformador sino porque se constituye en sí mismo como una medida de reparación a las víctimas en el sentido que reestablece un derecho vulnerado: la participación activa y libre.

De igual forma llama atención la masiva participación de los habitantes de Montes de María en los diferentes espacios propuestos para el proceso de formulación de los PDET y los PATR frente a otras regiones con similar número de municipios involucrados como el Chocó. Esta situación puede entenderse como un reflejo del fortalecimiento de los movimientos y organizaciones sociales de territorio y su empoderamiento como víctimas.

\subsection{Fortalecimiento del tejido social y generación de capacidades}

Una categoría de análisis central en el estudio psicosocial comunitario corresponde al "fortalecimiento", también llamado por distintos autores como "potenciación" o "apoderamiento", que para Montero (2003) hace referencia al:

Proceso mediante el cual los miembros de una comunidad (individuos interesados y grupos organizados) desarrollan conjuntamente capacidades y recursos para controlar su situación de vida, actuando de manera comprometida, consciente y crítica, para lograr la transformación de su entorno según sus necesidades y aspiraciones, transformándose al mismo tiempo a sí mismos. (2003: 7).

Estos procesos desencadenan el llamado "sentido de ser-en relación con el mundo" Kieffer (1982); lo cual se traduce en el "sentido de comunidad". De esta manera, según Montero (2003) los procesos que hacen posible el fortalecimiento de las comunidades, son:

La participación, sin la cual no puede fortalecerse una comunidad; la conciencia que permite superar las formas de entendimiento negativas y desmovilizadoras tales como la alienación, la ideologización y la pasividad; el ejercicio del control por parte de la comunidad; el poder, que acompaña al control; la politización considerada como la ocupación del espacio público y la conciencia de los derechos y deberes inherentes a la ciudadanía. 
Noción que a su vez acompaña al control y al poder; la autogestión que supone la involucración directa de las comunidades en sus procesos de transformación y asimismo, está ligada a las anteriores; el compromiso, que imprime a la acción el respeto y consideración por los otros, por la comunidad y por sí mismo; la evolución y crecimiento individual que permite emplear las propias capacidades, generando nuevas expresiones y desarrollando las que se tienen en función de los intereses comunitarios que benefician a todos. Y finalmente una forma de identidad social que supone una identidad comunitaria marcada por lo que se conoce en la literatura como sentido de comunidad. (2003: 6-7). (Cursivas nuestras).

Para las víctimas del conflicto armado en Colombia la participación en espacios de interlocución y deliberación comunitaria ha significado una apuesta por el fortalecimiento de los lazos comunitarios en pro de la trasformación positiva de un pasado violento, lo cual implica el desarrollo de ciertas capacidades centrales (Nussbaum, 2012, 2001) orientadas a la autogestión, movilización comunitaria, control social, resistencia comunitaria, liderazgos; capacidades mediadas por otras importantes a nivel individual como actitud crítica, propositiva, sentido de seren relación con la comunidad.

De acuerdo al enfoque de capacidades que se estructura desde los aportes realizados por Sen (2000) y Nussbaum (2012,2001) este contexto de violencia generalizado en la región, si bien afectó capacidades centrales como las de vida (al morir de forma prematura), de salud física (al ser desplazados y no poder contar con un lugar adecuado para vivir), integridad física (al no poder moverse libremente de un lugar a otros, ni estar protegidos de ataques violentos) y de control mate- rial y político sobre el propio entorno (al ser sus territorios sometidos a la voluntad de los grupos armados, sin posibilidad de participación o decisión), generó por otra parte el surgimiento y fortalecimiento de otras capacidades.

En ese sentido se observó que fue propiciado el fortalecimiento de la capacidad de afiliación en la medida en que la condición de víctimas y la vulnerabilidad asociada a esta dio el paso para un reconocimiento colectivo de esta condición, que permitiera el surgimiento de asociaciones, organizaciones y movimientos para emprender luchas en favor de sus derechos, y hacer parte de manera constante y activa de los espacios institucionales que se han venido abriendo para su participación.

De otra parte consolidó la capacidad de control político sobre el propio entorno (Nussbaum, 2012), al posibilitar el surgimiento de espacios de participación política desde lo popular e institucional para la incidencia en la toma de decisiones sobre sus derechos.

Asimismo, fortaleció la capacidad de razón práctica porque a través de los espacios de participación generados con el posconflicto, las comunidades han tenido la oportunidad de poner en debate sus propias visiones sobre desarrollo, planes y proyectos de vida comunitarios, formándose una concepción de bienestar para su población y permitiendo una reflexión crítica sobre los planes y proyectos que tienen pensados para sus vidas. (Nussbaum, 2012).

Estos procesos de apropiación comunitaria y potenciación de capacidades, están encaminados a la materialización de los proyectos de vida colectivos; donde la participación cobra un papel imprescindible 
"si no hay participación, no habrá ni eficacia psicopolítica ni sentido de ella, ni el poder y el control residirán en la comunidad." (Montero, 2003: 8). Fenómeno que refuerza lo planteado por Herrera (2008) "la visibilizaciòn de demandas como los derechos humanos deben servirnos para aumentar nuestra "potencia" y nuestra "capacidad" de actuar en el mundo" (Herrera, 2005: 71).

"Todo se ha venido cumpliendo parcialmente por una presión comunitaria; y uno pensaría que no quieren cumplir, pero cuando hablamos de reparación es porque estamos convencidos que tenemos ese derecho". (Participante, SRC Chengue, 2017)

Ante las ineficiencias institucionales para el cumplimiento de los PIRC, los SRC señalaron que optaron por organizarse como comunidad y auto-gestionar las acciones pertinentes para la ejecución de las medidas contempladas en el plan; para el caso del SRC de EI Salado, se precisó como medida de reparación simbólica: "garantizar que las familias recuperen los restos de sus víctimas y les den sepultura" (PIRC, El Salado).

Ante la inoperancia de los responsables de esta medida; la comunidad decidió efectuar presión a las autoridades competentes para la exhumación de los cadáveres de las víctimas de la Masacre del año 2000.

\footnotetext{
"Nosotros como comunidad emprendimos una lucha, presionamos para que se hiciera posible, y se logró por la lucha que emprendimos como comunidad, no por voluntad de la unidad, en eso acompañamos a los familiares de las víctimas mortales" (Participante grupo focal, SRC El salado).
}

Otra capacidad desarrollada como producto del fortalecimiento comunitario es la movilización; convertida por las víctimas como un dispositivo de presión con- tundente; es el caso del Sujeto de Reparación Colectiva de Alta Montaña, quien en el año 2013, debido a la agudización de las problemáticas sociales en el territorio, generadas por el abandono del Estado y los Gobiernos locales, decidió movilizase para exigir inversión social en las comunidades. Así, el 9 abril de ese año se movilizaron cerca de 1.000 personas de los corregimientos y veredas de Alta Montaña. Se logró el dialogo en Mesas y el pacto de compromisos con el Gobierno Nacional.

"Por problemas graves que ya estábamos teniendo, nos movilizamos más de 1000 personas por acá, en 2013" (Entrevista, SRC Alta Montaña, 2017).

Ese proceso que pone de manifiesto el poder de los movimientos sociales, cuando "...unen sus fuerzas para enfrentarse a las élites, a las autoridades y a sus antagonistas sociales. Crear, coordinar y mantener esta interacción es la contribución específica de los movimientos sociales, que surgen cuando se dan las oportunidades políticas para la intervención de agentes sociales que normalmente carecen de ellas. Estos movimientos atraen a la gente a la acción colectiva por medio de repertorios conocidos de enfrentamiento e introducen innovaciones en torno a sus márgenes. En su base se encuentran las redes sociales y los símbolos culturales a través de los cuales se estructuran las relaciones sociales. (Tarrow, 1977: 17).

Asimismo, producto de las movilizaciones y exigencias demandas por las victimas al Estado colombiano, se dio el reconocimiento y abordaje jurídico en la Ley 1448, del "daño colectivo" que contempla i) el daño ocasionado por la violación de los derechos colectivos; ii) la violación grave y manifiesta de los derechos indivi- 
duales de los miembros de los colectivos; y iii) el impacto colectivo de la violación de derechos individuales.

En la implementación de Ruta de Reparación Colectiva, los sujetos especificaron que fue indispensable la participación en las distintas actividades convocadas por las Organizaciones no gubernamentales y las Universidades, pues ello permitió adquirir conocimientos y apropiarse de discursos sobre la reparación colectiva, luego, esenciales en la creación de estrategias de presión institucional.

"La Universidad está haciendo acompañamiento al sujeto. También, la Fundación Abriendo Caminos ha estado apoyando en esto; y Manos a la Paz. Estas organizaciones nos ayudaron a preparar las propuestas, para que cuando vengan los de la Unidad, ya tengamos las propuestas. O sea cuando vengan estemos avanzados y entonces las personas que se delegaran se les comunicara para que sepan". (Participante grupo focal, SRC Chengue, 2017).

\section{Conclusiones}

Si bien el conflicto armado en Colombia dejó un saldo de graves violaciones de los Derechos Humanos, su apaciguamiento permitió no solo el retorno paulatino de las familias desplazadas a sus territorios, sino un proceso de reorganización de las comunidades victimizadas; primero alrededor de temas humanitarios y más tarde en la exigibilidad de derechos económicos, políticos, sociales y culturales; como la reactivación productiva, la protección y preservación de recursos naturales y la defensa del territorio como elemento central para la reparación de comunidades étnicas.
Aunque la formulación de los Planes Integrales de Reparación Colectiva (PIRC) y los Planes de Desarrollo Territorial (PDT), significaron pensar y diseñar la reparación desde el sentir de las víctimas en la configuración participativa de las acciones reparadoras; el incumplimiento de los compromisos pactados con el Estado ha provocado que los Sujetos de Reparación Colectiva (SRC) se armen con la creación y el fortalecimiento de espacios de deliberación e incidencia comunitaria; constituidos como disposiciones de resistencia, agencia territorial, control y presión institucional.

Otro elemento significativo resultante de la investigación, señala que la participación en las instancias de interlocución normalizadas se establece como un mecanismo de diálogo político entre las víctimas y el Estado, que obliga el reconocimiento de las víctimas como sujetos válidos de conocimiento, interlocución y trasformación. Asimismo, desde estos escenarios se abre la oportunidad para ejercer control a la gestión institucional en la atención y reparación; ahora los derechos sociales, económicos, políticos y culturales transgredidos por el Estado y los actores armados en el conflicto, pueden ser exigidos y vigilados mediante la participación en estos espacios.

Para los SRC, las prácticas de resistencias y potenciamiento comunitario coadyuvaron a la creación capacidades importantes referidas a la autogestión, movilización comunitaria, control social, liderazgos; intervenidas por otras significativas a nivel individual como actitud crítica, propositiva, y sentido de ser-en relación con la comunidad, desencadenando procesos organizativos que surgieron y se han fortalecido en esta etapa de 
posconflicto, como el de las comunidades étnicas afrodescendientes a través de la conformación de Consejos Comunitarios de Comunidades Negras y Afrocolombianas, logrando insertarse e incidir en los espacios institucionales de participación creados por las leyes.

En últimas, los resultados de la observación y acompañamiento a las comunidades y organizaciones de víctimas permiten afirmar que existen avances significativos en el desarrollo de capacidades para la agencia de las demandas territoriales de las víctimas; quienes mediante el fortalecimiento comunitario han auto-gestado prácticas sociales como el cabildeo y negociación con las autoridades locales e instituciones, para incidir en la formulación, ejecución, seguimiento/monitoreo de los planes, programas, proyecto y políticas públicas de reparación.

No obstante, se encontraron debilidades comunes para la incidencia real en los planes y programas que determinaran en largo plazo el desarrollo de los territorios, entre estas se resaltan la inexistencia de un sistema de información institucional, la insuficiente articulación con las autoridades locales, la carencia de un sistema de pesos y contrapesos que permitan equilibrar las condicione de poder de las victimas frente al Estado y los privados, la falta de voluntad política de los entes territoriales y organismos de control en el acompañamiento a la reparación, ausencia de control fiscal a la ejecución de los presupuestos destinados por ley a la reparación, e ineficiencia en las acciones institucionales para el seguimiento, monitoreo de las políticas y planes de reparación.

Es necesario - tal como lo exige la ley- garantizar unos mínimos recursos de fun- cionamiento para que los espacios de participación reflejen las demandas en cada territorio y respondan a los criterios de pertinencia y calidad para ser insertadas en la agenda pública de los gobiernos territoriales; accionar que no solo posibilita la recuperación de la confianza en un Estado social de Derecho fallido, sino que permite apostarle a la reconciliación nacional, la reparación integral y la construcción de una paz estable y duradera; si del cumplimiento del Acuerdo de Paz y las políticas públicas de reparación se tratase.

\section{Bibliografía}

Aguilera, M. (2002). "Palma africana en la Costa Caribe: Un semillero de empresas solidarias". Documentos de trabajo sobre economía regional. Banco de República. No. 30. Cartagena de Indias.

Agencia de renovación del Territorio. www.renovacionterritorio.gov.co. (Consulta 9 de noviembre de 2018).

Aldret, A. D. (2017) 'Participación ciudadana en la gestión y en las políticas públicas', Gestión y Política Pública, pp. 341-379.

Congreso de la República de Colombia. (2011). Ley 1448 de 2011. "Por la cual se dictan medidas de atención, asistencia y reparación integral a las víctimas del conflicto armado interno y se dictan otras disposiciones". Diario Oficial No. 48.096 de 10 de junio de 2011.

Contraloría General de la República (2017). "Análisis sobre los resultados y costos de la ley de justicia y paz". Bogotá. Available at: https://www.contraloria.gov. co/documents/20181/466201/Análisis+ sobre+los+resultados+y+costos+de+la+ Ley+de+Justicia+y+Paz/dcce2907-f66942b8-8857-7e14750cc467?version=1.0. 
Centro Nacional de Memoria Histórica. (2018). "Bases de datos, Observatorio de Memoria y Conflicto". fecha de corte: 15/09/2018.

Daniels, A (2016). "La transformación de la estructura productiva de los Montes de María: de despensa agrícola a distrito minero-energético". Revista Memorias. No.12. 2016

Herrera, J. (2008) La reinvención de los Derechos Humanos. Sevilla: Atrapasueños.

Hueso, A., Boni, A. y Belda-Miquel, S. (2015) 'Perspectivas y políticas sobre la juventud en desventaja en España: un análisis desde el enfoque de capacidades / Perspectives and Policies on Disadvantaged Youth in Spain: An Analysis Using the Capability Approach', Revista Española de Investigaciones Sociológicas, pp. 47-64. doi: 10.5477/cis/reis.152.47.

Muñoz, M. (2014) 'El enfoque de capacidad de Amartya Sen y sus limitaciones para la ciudadanía y la sociedad civil', Araucaria. Revista Iberoamericana de FiIosofía, Política y Humanidades, 31(16), pp. 85-103.

Nieto, J. (2014) "La participación como resistencia en el contexto del conflicto armado colombiano". FORUM, Revista del Departamento de Ciencia Política, 5, pp. 139-159.

Nussbaum, M. (2012) 'Las capacidades centrales', en Paidós (ed.) Crear capacidades, propuesta para el desarrollo humano. Barcelona: Espasa Libros, pp. 38-65.

Nussbaum, M. (2001). Women and human development: The capabilities approach (Vol. 3). Cambridge: Cambridge University Press.

Ojeda; D, Petzl; J, Quiroga; C (2015). "Paisajes del despojo cotidiano: aca- paramiento de tierra y agua en Montes de María, Colombia ", Revista de Estudios Sociales [En línea], 54 I Octubre de 2015, disponible en http://journals.openedition.org/revestudsoc/949 (Consulta 12 de noviembre de 2018)

Parés, M. (2009) 'Introducción: Participación y evaluación de la participación', en Participación y calidad democrática: Evaluando las nuevas formas de democracia participativa. Barcelona: Ariel, pp. 15-26.

Rodríguez, C. y Rodríguez, D. (2010) Cortes y cambio social. Cómo la Corte Constitucional transformó el despazamiento forzado en Colombia. Bogotá: Centro de Estudios de Derecho, Justicia y Sociedad.

Sen, A. (1999a) 'Democracy as a Universal Value', Journal of Democracy, 10 (3), pp. 3-17.

Sen, A. (1999b). Development as freedom. Nueva York: O. U. Press.

Subirats, J. (2005) 'Democracia, participación y transformacion social', Polis, Revista Latinoamericana, 12, pp. 1-10. Unidad para la Atención y Reparación Integral a las Víctimas. (2013). Resolución 0388 de 2013. "Por la cual se adopta el Protocolo de Participación Efectiva de las Víctimas del Conflicto Armado". Diario Oficial 48796, de 20 de mayo de 2913.

Vargas, J. (2014) 'Análisis comparativo de los diseños institucionales que regulan la participación de las víctimas en Colombia: antes y después de la Ley 1448 de 2012', Estudios Socio-Jurídicos, 16 (1), pp. 167-207. doi: 10.12804/ esj16.1.2014.04.

Victorino, R. (2011). Transformaciones territoriales a partir del abandono y despojo de tierras asociado a la acción de grupos armados. El caso de Marialaba- 
ja departamento de Bolívar. (Tesis de maestría). Pontificia Universidad Javeriana. Bogotá.

Villa, J. D. y Insuasty, A. (2016) 'Entre la Participación y la Resistencia: Reconstrucción del Tejido Social desde Abajo en el Municipio de San Carlos más allá de la Lógica de Reparación Estatal', Agora U.S.B., 16 (2), p. 453. doi: 10.21500/16578031.2442. 